\title{
From Planned to Transformative Urbanization: Analyzing India's Policies of Urban Rejuvenation
}

\author{
Mihir Bholey \\ Senior Faculty, Interdisciplinary Design Studies \\ National Institute of Design, PG Campus, Gandhinagar, India.
}

\begin{abstract}
This paper examines India's urban challenges, successive policies of urban development and their impact on the much needed urban transformation. It examines successive policies, plans, and approaches to meet the ever rising urban challenges from the first Five Year Plan till the end of planning era and also underscores the highlights of urban planning through the entire five-year plan period. In the process, it investigates whether the ubiquitous urban deficit in India is actually due to the so-called 'reluctant urbanization' and whether the current policy of creating hundred smart cities can lead to urban transformation in India. This paper is based on the analysis of the available secondary data from various sources. By critically examining the available secondary data this paper explores whether India's urban deficit is a result of poor planning or lack of long term vision and strategy to meet the emerging urban challenges. This paper also critically looks into the emerging ICT-driven paradigms and design of the 'smart cities' as models of urban transformation and juxtaposes them to India's own vision of creating hundred smart cities to ensure urban transformation. The paper concludes that any urban transformation should be socially inclusive, economically viable and environmentally sustainable. Technology should not be the end rather the means for bringing urban transformation and building smart cities.
\end{abstract}

Keywords: Urbanization, urban transformation, smart city, planning, design, ICT, technology, policy

\section{Urbanization: The Ongoing Process}

In rather simplistic terms urbanization refers to either relocation or migration of population from the countryside to cities often in the pursuit of a job, the superior quality of life, financial well-being and better opportunities among others. This process largely remains the raison d'être of urbanization. The course of urban evolution is a historical one and has been going on for ages. What has gone hand in hand with it is the substitution of the native rural culture by dominant urban culture across the world. Thus urbanism, which characterizes urbanization, also refers to a different way of life both in terms of aspirations and expressions. It's widely accepted that urbanization happens when three-fourths of the entire population of an area is engaged in an occupation which is not agriculture. However, no single definition seems to define it comprehensively because of the layers of complexity associated with the process of urbanization. Near synonymous expressions like the city, an urban agglomeration, urban sprawl, metropolitan, peri-urban, etc. make the concept all the more complicated.

The definitions of urbanization address to a variety of concepts. Thompson (1935), who explained it in terms of occupational engagement, said, "Urbanization is characterized by movements of people from small communities 
concerned chiefly or solely with agricultural to other communities generally larger, whose activities are primarily centered in Government, trade, manufacture, or allied interests." Change in the pattern of population distribution is another aspect which Hauser and Duncan (1959) underscore in their definition of urbanization.McGranahan and Satterthwaite (2014) point out that "Urbanisation is often used more loosely, however, to refer to a broad-based rural-to-urban transition involving population, land use, economic activity, and culture, or indeed any one of these."The process of 'urban transition' has also been explained and emphasized by Montgomery et al., (2004) in a similar manner. The definitions describe urbanization as a transfer of a population from small rural settlements which relies on agriculture as the major economic activity to places which are not only different in terms of population density but also in terms of occupation which employs them either in the industrial or service sectors. They explain the phenomenon from the perspectives of rural-urban transition, population density, occupation, land use pattern, livelihood opportunities, etc.

Nevertheless, urbanization is not just the story of demographic and occupational changes, but also a parallel oftentimes concurrent growth of human aspirations for a different (generally considered better) quality of life, driven by evolving technology, innovation, a plethora of economic activities and so on. Each one of them contributes to the mutating socio-cultural-economic-political-spatial-design and sustainability challenges. If growth is what characterizes urbanization, rapid and unplanned growth are creating humongous problems of socio-economic and environmental sustainability. As per World Urbanization Prospects: The 2014 Revision report, in the year 2012 close to 863 million people, comprising of nearly one-third of urban residents in developing regions, living in slums or informal settlements deprived of access to improved water and sanitation or any security against eviction. Nevertheless, ever since 1950, it has picked up a faster pace and urban population has experienced exponential growth from 751 million to 4.2 billion in 2018. As compared to that, global rural population growth had been rather sluggish since 1950 .

The data of rural-urban population change is important not only to know the trend but also to assess the preparedness to meet the imminent challenges of urbanization. As per the United Nations Department of Economic and Social Affairs (UN DESA 2018) report the present 55\% of the world's population living in urban areas, is expected to increase to $68 \%$ by 2050 . It also estimates current (2018) global rural population to be close to 3.4 billion. After a slight rise, it is envisaged to further decline and settle around 3.1 billion in 2050. All these demographic changes are happening in a span of 100 years. 90 percent of world's rural population still lives in Asia and Africa (till 2018) and out of this India's share of the rural population is the highest (893 million) followed by China (578 million), the report states. It's the size of India's rural population which is going to remain the potential source of rapid urbanization in India for many more years to come. As per the projections of the World Urbanization Prospects: 2018 Revision report, India together with China and Nigeria alone is going to add 35\% to the global urban population from 2018 to 2050 . India's urban population is likely to become 416 million as per the projection. In the light of these projections the level of India's preparedness to deal with this imminent challenge is always questioned.

However, under the overwhelming impact of data, an important aspect is often ignored in the discourse of urbanization. It is about emphasizing the need for augmenting rural-urban coexistence rather than creating the ruralurban binary. This binary complicates the problem as it affects the symbiotic relation between urban and rural in traditional societies like India which are going through the phase of socio-economic transformation. Sustainable urbanization will not be possible in the absence of sustainable models of rural development because rural-urban ecosystem is synergetic in nature. Their coexistence is important for their socio-economic growth and sustenance. A study by Lanjouw and Murgai (2010) shows the evidence of such synergy. It highlights the strong association between urban growth and rural non-farm sector particularly if the urban center is a small town and not a large city. Another study by Lanjouw and Murgai (2019) highlights that in rural Brazil incidence of poverty is found to be lower in those rural areas which are surrounded by such urban centers where the rate of poverty is low. Indian cities are also dependent on their surrounding rural areas for the seamless supply of food, goods, natural resources, manpower etc. while the villages depend on cities for employment, education, healthcare and so on. This urban-rural metabolism is essential for supporting sustainable human habitat.

\section{India's Urbanization: An Overview}

A city is not just a spatial or architectural design. It's a series of mutually interacting systems of which physical part is one (Vale and Vale, 1996). India's urbanization is no exception to this. Urbanization in India is not just a phenomenon of demographic change but a rapid socio-cultural-economic and technological transformation of a 
society which cherished and even eulogized the simplicity of rural life for a long time. The country was always referred to as the 'country of villages' and one whose soul rested in villages. So much so, that bending over villages was considered 'politically correct'. Hence, for a long time, it conveniently ignored the consistent urban transformation of society and its rising demands. The observation of Ahluwalia (2017) is worth noting. She points out that the "political economy of development in India has remained dominantly concerned with the development of rural areas implicitly assuming that urban areas can take care of themselves." Not only that, even for making the strategy for the development of economy their role has been overlooked, Ahluwalia asserts.

With the advent of the 20th century, India embarked into the era of rapid urbanization. In a hundred years between 1901-2001, its share of urban population increased from 11 to over 28 percent and total urban agglomeration increased from 1827 to 4386 . As per the Government of India 2011 census, the total number of cities in India is 7,933 which include both the statutory and census towns. The year 1981 experienced the highest annual growth rate of urbanization which was 3.83 percent (Batra, 2009). Worldometers, which calculates real-time data, estimates India's urbanization in 2019 as 33.6 percent while the total urban population is estimated to be $460,249,853$. The percentage of decadal change in India's urban population vis-à-vis the rural population (Figure: 1) has also been significant. Figure 1 below shows the decadal change in India's urban population vis a vis the change in rural population.

Figure 1: Percentage Decadal Change in Urban Population in India

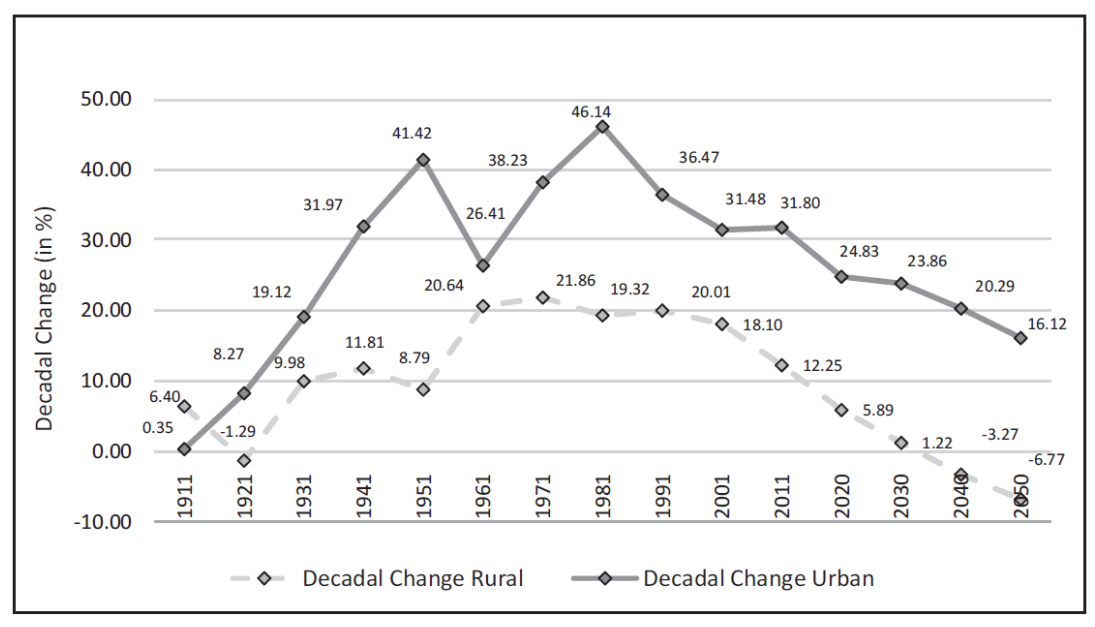

Source: Measuring Urbanisation in India. ORF Issue Brief. Dec. 2017. Issue 218

Not only that, the urban population of India is way ahead of the combined population of East Africa, West Asia, Western Europe or the total population of Brazil and US separately. Nearly one-fourth of the urban population lives in slums. Economic unsustainability is a major concern arising out of lack of a wide spectrum of employment opportunities and a high cost of living. Most of the jobs in the cities in recent years are white collar jobs. But despite the visible socio-economic disparity Indian cities are emerging as the highest contributors to GDP. As per McKinsey (2014) report 'Understanding India's economic geography' there were 54 metropolitan cities in India in the year 2012. They accounted for 40 percent of the GDP. The report estimates by 2025 India will have 69 metropolitan cities. Together with their hinterland, they will account for 54 percent of the country's incremental GDP from 20122025.

The rising global interest in India has made different agencies and organizations analyze its data pertaining to urbanization from different perspectives. The variance in data that one comes across is often because of the number of studies, difference in method, approach, and analysis. There's no doubt that India's urban trajectory has global significance because it's closely connected to its economic trajectory, patterns of consumption, climate change among others. Besides, it also needs interventions at several levels ranging from policy to finance, management, technology, and design. The urban deficit can be identified at all these levels and many more. For example, just for meeting the shortage of 110 million units of housing by 2022, as per the KPMG report (2017) on India's Real 
Estate, the estimated expenditure would amount to USD 2 trillion (INR130 trillion). Not only this, any modern intervention (as in the case of smart cities) will require lots of supportive technologically advanced infrastructure. Hence, for the supportive urban infrastructure, including utility services, will require another USD1.0 -1.5 trillion (INR $65-97$ trillion) by 2030.

\section{The Challenges of Urbanization in India}

Of late, India's urban demography has changed at an unprecedented speed. It is not only creating huge demand for urban space and amenities but also sending warning signals of the perpetual infrastructure deficit. Lack of a dedicated pool of professional urban managers (planners, designers, engineers, and administrators included), financial crunch, comprehensive and futuristic vision are some of the obvious challenges facing India's urban rejuvenation. Incessant urban influx makes the situation even more complicated. At the very basic level country faces the challenge of providing its 377 million urban population (as per 2011 census data), safe water, sanitation, housing, healthcare, energy, services of waste management, etc. as the basic requirement. They remain the core areas of intervention even under the smart city mission which aims at developing a comprehensive eco-system based on the four pillars namely - development-institutional, physical, social and economic infrastructure.

Paul (2010) identifies urban weaknesses at three fronts namely: (1) infrastructure, (2) finance and (3) governance responsible for the urban problems. Though they remain the basic necessities of a city. However, when it comes to smart city, the new aspiration for urban rejuvenation, these services are required to be augmented with smart interventions in the form of ICT infrastructure, technology, and design as well. Most of the cities are not fully geared up yet to move to the next trajectory. Like everywhere else, cities in India too have evolved from a simple to a more complex urban system. It's visible in its demography, system, design, infrastructure, management and so on. Marshall (2012) looks at urban evolution as a continuous process that applies as much today as in the past. That is, evolutionary urbanism is not some rudimentary historic process that was supplanted by modern town planning. The challenges these evolution poses are humongous. Figure 2 explains some basic aspects of urban challenges.

Figure 2: India' Urban Challenges at a Glimpse

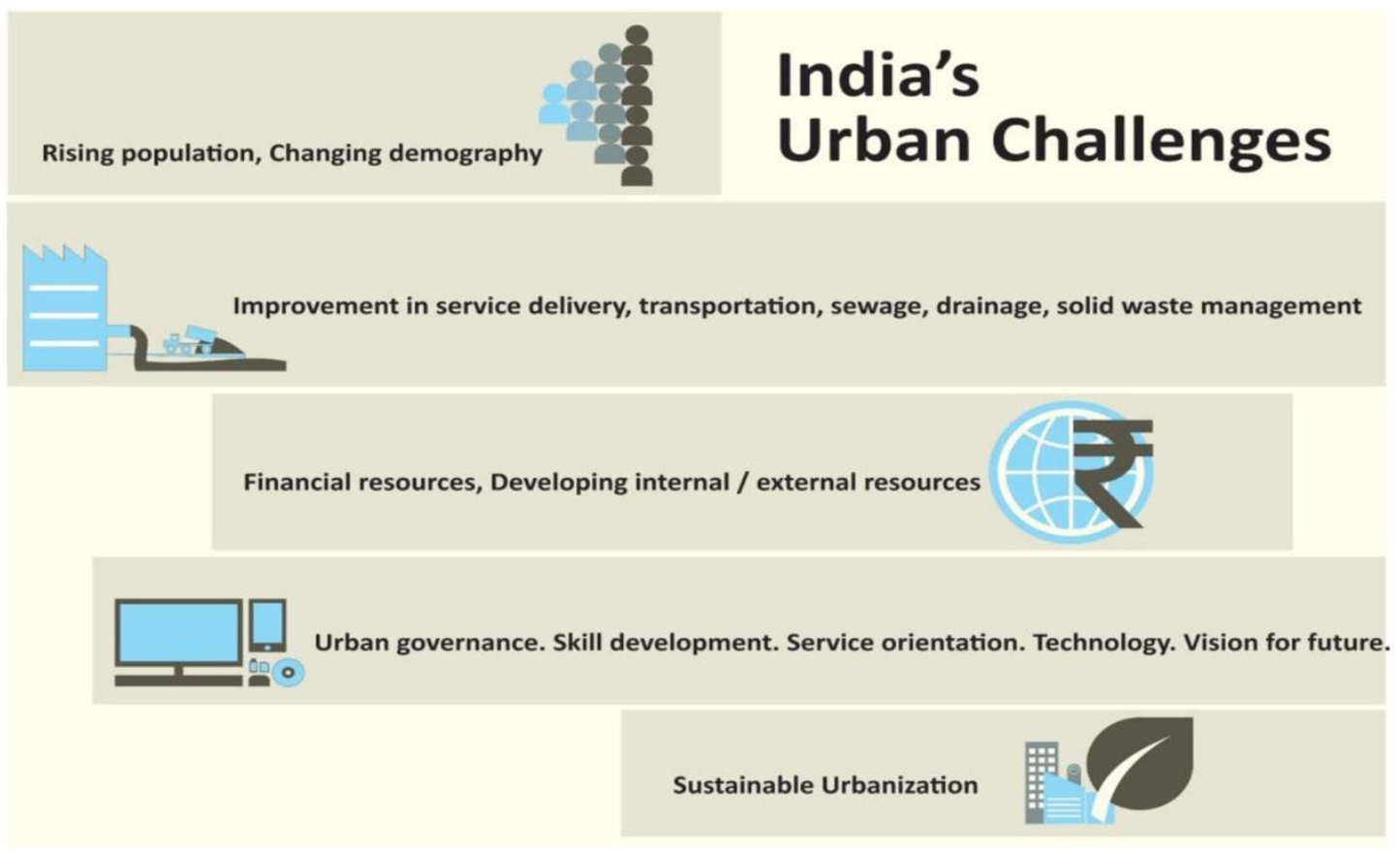

India's Urban Challenges. Conceptual Model: Mihir Bholey 
From the policy perspective, inclusive urban development has been an important element of India's policy framework. Hence, cities are also supposed to be inclusive in nature providing infrastructure and basic amenities to rich and poor alike. To ensure services like housing, road, public transport, water and sanitation, electricity remains at the core of urban management. Making these services available and affordable to the poor is a big challenge. However, it is ironical that despite the apparent pro-poor policies of the successive governments, there is a stark deficit of such amenities. Lack of proper housing for the urban poor, for example, has resulted in the mushrooming of slums across all Indian cities, particularly in the big ones. The gap between demand and supply persists despite the aspiration and articulation to ameliorate the situation. Bholey (2016) writes:

"The question inevitably arises - where is the gap, whether at the policy or at implementation level? A democratic constitution that India has, nurtures the ideal of social inclusion in words and spirit. Good governance and satisfactory service delivery are some of the basic expectations of the people from the government. However, converting spirit into action is often better said than done."

Ernst \& Young (EY) 2017 report on India's Growth Paradigm estimated India's urban population to be 420 million in 2015. By 2020, it calculates 50 million more will be added making the estimated urban population to 470 million. Empirical data revealing the real extent of urbanization in India is somewhat debatable. The estimation of India's urbanization varies between 26.29 percent to 33.6 percent in 2019 . The reason is largely due to the ambiguity and differences in defining exactly what should be called urban. Hence, the foremost challenge is arriving at a unanimous definition of urbanization in India. The varied existing methods and vagueness make measuring urbanization in India a difficult task. It manifests in India's widespread urban chaos and mismanagement.

Management Guru Peter Drucker says: "What gets measured, gets managed". Availability of actual, extensive, realtime data remains a problem which reflects in unsatisfactory urban management. Besides, the vagueness in definition also allows bureaucratic arbitrariness in identifying urban sprawls and ensuring their management. Urban development in India is a state subject, as such notifying an area as urban comes under the purview of the states. Notification is made if an area qualifies for the administrative definition which takes into account factors such as population and density of the population in the area, revenue generation for local administration, non-agricultural employment percentage among other.

Besides administrative, there's census definition as well by the central government which is based on the census report. It takes into consideration factors like minimum 5000 population and a population density of 400 persons per square $\mathrm{km}$ of which 75 percent male being employed in activities other than agriculture, the existence of urban local government (i.e., statutory towns notified by the state government) among other. Thus, as per state government (statutory) definition, 26.69 percent of India was urbanized till the last census of 2011 while as per the census definition the figure was 31.15 percent. Having a Gram Panchayat(rural self-government) within city limit is also not an uncommon experience in India which characterizes the rurban (rural-urban in one) nature of Indian cities.

Cities today are an embodiment of global benchmarks and local aspirations. They are supposed to go in tandem with each other. The influence of global systems, design, and aspirations are more pronounced than ever before. Sassen (2001) describes global cities as strategic sites. They are places were transnational processes happen at the national level and international dynamics comes into action through national, regional and local institutional arrangements. United Nation's Sustainable Development Goal (2015) also considers urban development as a major thrust area. Its Goal 11 which is about Sustainable Cities and Communities (Figure 3) underscores the need for making cities and human settlements inclusive, safe, resilient and sustainable. 
Figure 3. Sustainable Development Goals (SDGs)

\section{SUSTAINABLE
DEVELOPMENT
GE'AALS}
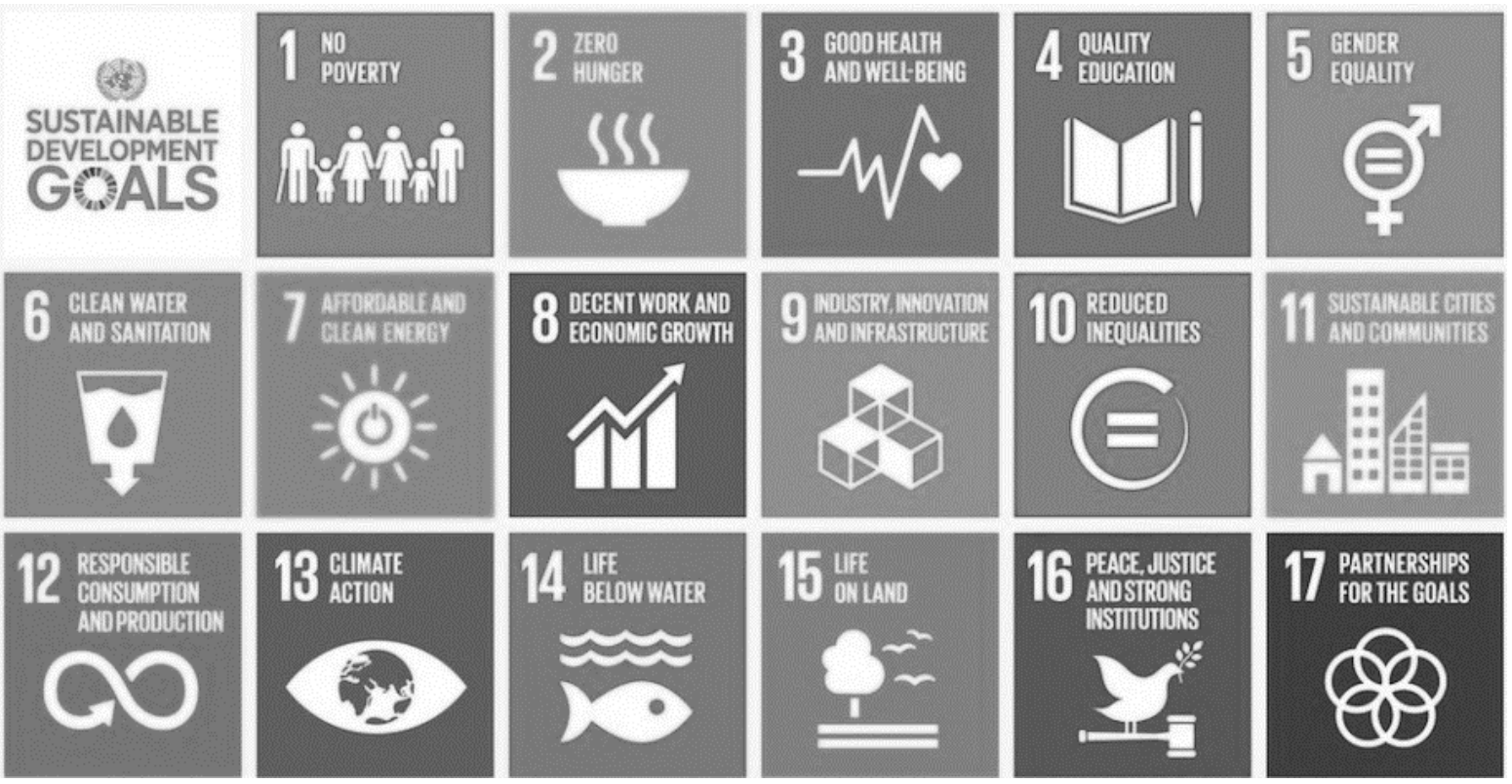

Source: un.org/sustainabledevelopment/blog/2017/09/un-chief-outlines-strategy-to-reshape-global-finance-forsustainable-development/

Cities these days are also considered to be 'the major platform for transformation, the locus for change and the venue where the human agency might be mobilized' (Mukherjee, 2018). So the challenges Indian cities face are not just confined to improving the civic amenities and infrastructure, but to align the urban eco-system with the global mandates and vision of sustainable development as well.

\section{Urbanization through the Plan Period}

Though India created various institutions and organizations for urban development such as Delhi Development Authority, National Building Organization among other during the first two five-year plan periods itself. The third five-year plan (1961-66) even underscored the relevance of cities in balanced regional development. However, despite having successive policies of urban development throughout the plan period India had been somewhat reluctant (Ahluwalia et al., 2014 \& Tiwari et al., 2015) to accept the importance of urban transformation. The reluctance was visible at the political and policy level because for long India was considered to be a country that lived in villages and the contribution of cities in social-economic and cultural development were largely underplayed. In the post-independence era, Gandhian model of Indian society was the underlying guiding principle. Gandhi's concept and model of Gram Swaraj which envisioned villages as self-sufficient and self-reliant independent republics, capable of managing their own affairs without depending on others for fulfilling major needs cast a profound influence on planning process and priorities.

According to Gandhi, his idea of Gram Swaraj was "a complete republic, independent of its neighbor for its own vital wants and yet interdependent for many in which dependence is a necessity." Gandhi believed in the distribution of political power among the people living in villages to ensure a real semblance of democracy. The term 'Swaraj' conveyed that idea. In Gandhi's viewsSwaraj in a real sense could only be delivered through autonomous, selfreliant communities that allowed opportunities to the people for fullest participation. It obviously referred to communities living in villages. Hence, underscoring urban needs could have been politically incorrect. Later during the plan period, Gandhian philosophy influenced the priorities of the governments of the day. Even the Nehruvian vision of modern India remained silent about the need for urban development in the creation of modern 
industrialized society. Lack of explicit constitutional status of cities and towns which people referred as anti-urban bias (Raheja, 1973) and absence of empathy regarding urban issues in the early years of the plan period in India was a kind of residual nationalist legacy of developing villages (Batra, 2012). The obvious reluctance to recognize the need for cities growth and development impacted India's overall urban development.

However, the reluctance did not mean a complete lack of vision and initiative towards urban development and its needs. For example, the $1^{\mathrm{st}}$ Five Year Plan (1951-56) looked at urbanization from the perspective of "proliferation of labour camps caused by rural to urban migration". Hence, the shortage of housing and the inflationary nature of land prices were taken into consideration. This led to some significant initiatives such as creating the Ministry of Working and Housing, National Building Organization, Town \& Country Planning Organization and Housing Board (Sharma, 2014). Consequently, during 1951-1960 several schemes to meet the housing demand viz. Subsidized Housing Scheme for Industrial Workers and Economically Weaker Section (1952), Low Income Group Housing Scheme (1954), Subsidized Housing Scheme for Plantation Workers (1956), Slum Clearance and Improvement Scheme (1956), Village Housing Project Scheme (1957), Middle Income Group Housing Scheme (1959) came into existence.

The 2nd Plan (1956-61) noted and raised a concern about the rising price of urban land and the speculative buying besides high rentals particularly in big cities. The plan attributed it to the growing industrialization. To counter the problem the theme of regional plan and emphasis on preparing urban master plan was introduced for the first time under the $2^{\text {nd }}$ plan period. To make up the deficit of urban housing scheme for construction of housing for the lowincome group was proposed. The Slums Area (Improvement and Clearance) Act was passed in 1956. It recognized slums as any area where houses are unfit for living, where buildings are dilapidated, the area is overcrowded and their arrangement and design is faulty. In short, habitats which are "detrimental, to safety, health or morals." The concern for the marginalized and need for the development of the roadmap for future development was obvious in this plan. Keeping the poor and marginalized sections in mind providing minimum standards of environmental hygiene and essential civic amenities and keeping rents within the paying capacity of the slum dwellers was emphasized. The plan for urban development recognized the housing deficit and focused on the expansion of housing facility which continued in the third plan as well. Over all, it articulated the need for devising methods to achieve planned urban development, expansion of housing facilities and development of a progressive civic administration.

The $3^{\text {rd }}$ five-year plan (1961- 66) also laid emphasis on housing and urban and rural planning. It allocated Rs. 142 crore or 14.2 million for housing and urban development. Its salient features were to recognize the importance of towns and cities in India's balanced development. It was during this plan period that adopting a regional approach for urban planning was advised. Besides, it highlighted the need for the preparation of a master plan for bigger cities, urban land regulation and controlling land prices for proper urbanization. Housing for lower income group, plantation workers, MIG housing, rental housing, removal of slums were some of the major recommendations for inclusive urban development. These recommendations still survive in their new avatars viz. Rajiv AwasYojna, PradhanmantriAwasYojana, IndiraAwasYojana (for rural housing).

The emphasis of the $4^{\text {th }}$ plan (1969-74) was on achieving balanced urban growth by easing the pressure on big cities through scatteringurban populations in smaller urban centers. Hence, regional studies of the areas in the vicinity of metropolitan cities including Delhi, Mumbai, and Calcutta (now Kolkata) were undertaken. Besides, governmentfunded special grants to speed up the development of new state capitals namely Chandigarh, Bhubaneshwar, Bhopal, and Gandhinagar. While regional and urban development initiatives remained at the core, the fourth five-year plan included the development of 72 urban centers. Not only that, but the plan also stressed upon the need to mend urban legislations and identify the statutes coming in way of urban development. For providing loan to state housing boards and urban development authorities Housing and Urban Development Corporation (HUDCO) was set up in 1970 which played a major role in supporting urban housing needs of the poor and disadvantaged sections. Nearly 95 percent of residential housingsupported by HUDCO cater to the economically weaker sections and people of lower income group category.

If balanced urban planning and provision of housing were the priority of the $4^{\text {th }}$ plan, the $5^{\text {th }}$ plan (1974-79) stressed upon controlling land prices in order to develop medium and small town and augmenting their services.In 1975, 
Task force on Planning and Development of Small and Medium Towns was also set up. It was supposed to examine laws relating to local administration and urban development. Besides, the task force was also expected to suggest suitable modifications in the laws so as to assist in the planned growth of small and medium towns among others (Routray, 1993). Addressing the infrastructure deficit of cities having a population in access of 300,000 was also emphasized under this plan and to achieve that Integrated Urban Development Programme (IUDP) was launched. Housing being a priority checking urban land price was a great challenge. Hence, in 1976 the government launched the Urban Land (Ceiling and Regulation) Act (ULCRA), 1976. It was one of the major steps towards planned urbanization in India.

Besides the development of metropolitan cities, mid-size cities also figured in the planning process. Batra (2009) observes "the focus of the 6th Plan (1980-85) was largely on the development of small and medium towns and provision of basic services in urban slums."Improvement in the condition of basic urban amenities such as sewage, sanitation, etc. Was underscored in the plan which is still a challenge for the proposed smart cities. However, it was the introduction of Integrated Development of Small and Medium Towns (IDSMT) meant to provide basic infrastructure and services to the cities having less than 1000,000 population which was a major policy direction under the plan. The national planning for urbanization lacked the vision and projection of the future so far and just responded to the needs of the cities as they emerged. Removal of slums and promise of providing them better civic amenities proved politically counterproductive in 1976 when nearly 0.7 million people were evicted in Delhi and relocated on the outer part of the city without any amenities or source of livelihood. It was seen as a big blow to India's commitment to socialism and inclusive development.

India's orientation towards economic liberalization started setting in from mid-eighties. The reflection was somewhat visible in the $7^{\text {th }}$ plan (1985-90). The scope was provided for the private sector in urban development which paved way for their entry into housing and real estate. Thus, as per the plan, the role of government was confined to the mere mobilization of resources for housing, making provision for low-cost housing for economically weaker sections and acquisition and development of land. The first ever National Housing Policy (NHP) was also introduced in 1988 to eradicate the problem of homelessness. To salvage city like Delhi which was reeling under the population pressure National Capital Region Planning Board was set up. The purpose was to divert the pressure on the cities of the adjoining states namely Haryana and UP. Today NCR has emerged a huge urban agglomeration comprising of cities like Gurgaon, Faridabad, Noida, and Ghaziabad among others. As per the notification NCR includes the whole of NCT-Delhi and certain districts of Haryana, Uttar Pradesh, and Rajasthan. The total area covered is about 30,242 sq. km. And the population is 37.03 million (as per 2001 census) (Report of the Study Group on NCR Policy Zones, Demographic Profile and Settlement Pattern, 2001). Managing this geographical spread and population remains a big challenge for urban planners.

One of the landmark steps in the direction of empowering and strengthening the process of urbanization happened during the $8^{\text {th }}$ plan period (1992-97) which saw the promulgation of a $74^{\text {th }}$ constitutional amendment. The amendment paved the way for the creation of elected urban local bodies (ULBs) and thus the decision making with regard to urbanization was decentralized. Autonomy in terms of economic planning made it possible to find alternate resources of finance, use institutional finance and issue market instruments such as municipal bonds to meet capital investment requirements. It was a big milestone towards economic empowerment.

The $9^{\text {th }}$ plan, (1997-2002) which coincided with 50 years of India's independence, was considered a bridge between fast economic growth and improvement in the quality of life of the people at large. Consequently, its outlook was described as "Growth with Social Justice and Equity".The need of greater fiscal autonomy to the ULBs was also highlighted in the India Infrastructure Report (2001). In the report, Mathur (2001) also suggested the need of developing innovative strategies by the ULBs to finance urban infrastructure and services so that 'the existing funds available from plan allocation could be supplemented by accessing the capital market.' While the plan proposed to make ULBs accountable for their financial viability by cutting down their budgetary allocation, it at the same time recognized the inability of small municipalities in arranging funds from financial and capital markets. To overcome regional disparity states were asked to play a major role. Creation of 'Urban Development Fund' guided by the principle of 'pooled finance' was a major policy initiative for the urban rejuvenation. It was meant to help small towns in commercial borrowing. Making cities economically viable, creation of employment, affordable housing, and infrastructure development were some of the major thrust areas under this plan. The market friendly initiative of allowing 100 percent FDI in infrastructure projects viz. road, the mass rapid transit system was also introduced 
during this pan itself. Repealing of the Urban Land Ceiling Act of 1976 in the year 1999 was yet another major step towards integrating urban development with economic growth. Launch of SwarnaJayantiShahariRozgarYojana (SJSRY) in Dec. 1997 was a step towards ensuring inclusive urban development and provide employment to the urban unemployed and underemployed with emphasis on self-employment.

In order to carry out comprehensive urban reforms, the $10^{\text {th }}$ plan (2002-2007) introduced some major policy push. Launching of the flagship scheme Jawaharlal Nehru National Urban Renewal Mission (JNNURM) in 2005 by the Ministry of Housing and Urban Affairs (MoUHPA) was one of them. The scheme was meant to provide "Basic Services for Urban Poor (BSUP) and Integrated Housing and Slum Development Programme (IHSDP)" and "aimed at integrated development of slums through projects for providing shelter, basic services and other related civic amenities with a view to providing utilities to the urban poor" (MoUHPA, 2019). It was run in a mission mode and identified 65 cities on the basis of their population and cultural significance to be covered under BSUP. The rest were covered under IHSDP. It aimed at providing affordable housing, water, sanitation, education, health, and social security to the urban poor in a time-bound manner for which 25 percent of the municipal budget was earmarked. This mission initially planned to conclude in March 2012 was extended for the next three years. Though it remained a major scheme of urban rejuvenation in recent years, its larger benefits remained confined to some major states like Maharashtra, Gujarat, Delhi, UP, West Bengal and Rajasthan which also received a more central allocation for IHSDP and BSUP (Kamath \& Zachariah, 2015). Thus, the equal pan-India impact was not seen.

The urban development agenda under the $11^{\text {th }}$ plan period (2007-12) began with the urban population base of 331 million. It was envisaged that during the plan period 36.8 million people would be added to the existing number. Thus, it was an additional absorption of 7-8 million people per annum in the cities for which planning was required. The strategy of urban development included the following measures:

Strengthening urban local bodies through capacity building and better financial management. Increasing the efficiency and productivity of cities by deregulation and development of land. Dismantling public sector monopoly over urban infrastructure and creating a conducive atmosphere for the private sector to invest. Establishing an autonomous regulatory framework to oversee the functioning of the public and private sector. Reducing the incidence of poverty. Using technology and innovation in a big way.(Planning Commission, $11^{\text {th }}$ Five Year Plan, 2007-12 Volume III)

JNNURM, launched during the previous plan remained a major initiative during the $11^{\text {th }}$ plan period as well. However, like other programmes, JNNURM also suffered from various inadequacies in terms of mainstream urban planning, incomplete reforms and delay in project implementation (Urban Development, Planning Commission). It was observed that due to lack of planning and ownership there was an uncontrolled and haphazard development of the peri-urban areas around the peripheries of the cities. Good service delivery was lacking in many cases. During the same plan period, yet another initiative for providing housing to the urban poor was launched under Rajiv AwasYojana in 2011. This was yet another attempt to make India slum free.

The $12^{\text {th }}$ five-year plan (2012-17) was the last in the list. The planning era came to an end with that. Planning Commission itself was replaced by National Institution for Transforming India popularly known as NITI Aayog in 2015. India now has a policy think tank at the place of the policy planning agency. Nevertheless, from the perspective of urbanization, it was significant as it envisioned smart cities and their role as being the engines of growth for the nation. As per the vision of the Planning Commission "cities must provide world class infrastructure and services at affordable costs to give a competitive edge to the economic activities they host."(Urban Development, Planning Commission). Besides, the permanent residents it also recognized the influx of migrant workers, their families and other vulnerable sections of society and the basic services they require. It worked with the overriding principle that urban agenda should be people-centric and they should have a larger say in envisioning the city and finding the way to achieve the goal. Figure 3 presents some of the important initiatives of urban transformation during the plan period. 
Figure 4.

Initiatives of Urban Transformation through the Plan Period

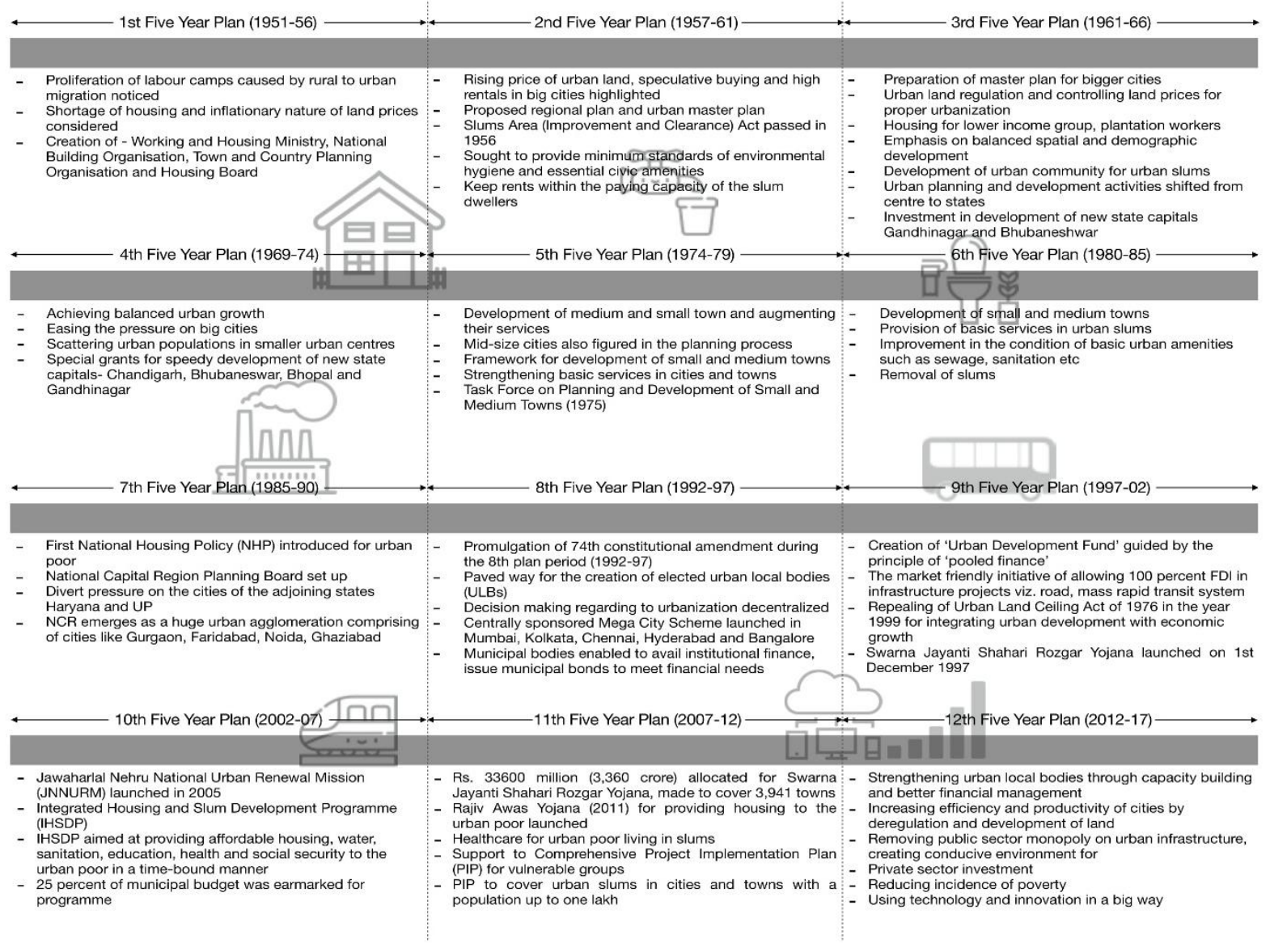

\section{Highlights of the Plan Period}

A comprehensive view of India's urban evolution through the plan period highlights the nature of urban challenges and the processes adopted to meet them from time to time. Social inclusion and empathy for the weaker and marginalized remained the guiding spirit of all plans related to urban development. However, what was often lacking was the wherewithal to execute the plans effectively. Despite recognizing the need of balanced urban growth during the $4^{\text {th }}$ plan period itself, regional imbalance of urbanization could not be addressed. Some of India's major states like UP, Bihar, Rajasthan, Odisha, Assam still rank very low in terms of urbanization and urban population. Ranking $34^{\text {th }}$ on the scale of urbanization, Bihar's urban population is still 11.3 percent $(2011$ data). The overwhelming population of Bihar is still rural. Thus the large outflux of people from the less urbanized states to big cities of other states puts tremendous pressure on their already stretched infrastructure.

From concentrating on basic interventions for urban development to envisioning cities as the growth engine of the economy shows the transformation in approach. The actual result on the ground may, however, take some time to be visible. It's also conspicuous that while urban development may be considered the plan period paradigm, urban transformation is it's present imperative. The policy of building a hundred smart cities reflect that urgency when urban growth is not only happening in big cities but is spreading to peri-urban areas and small cities. Centre for Policy Research (2015) data indicates that most of the new towns in 2011 are census towns. The population share of smaller towns is growing and the share of census towns has doubled since 2001. Referring to the LSE (2009) report Tiwari et al. (2015) point out that while the quality of life for the "haves" in Indian cities may be equal to Latin American cities, the "have not" may have it similar to that of many Sub-Saharan African nations. This is a big 
challenge for India. The development deficit is still at the very basic level of housing, water, and sanitation, road, energy, etc. As such, turning Indian cities into smart cities require a quantum jump.

\section{Urban Transformation and Smart Cities}

Urban experts and planners feel that to meet the imminent challenges of urbanization India needs extensive urban transformation and redesign its cities as smart cities. Though the concept of a smart city may be new to India's urban planning and management ethos, it was envisioned decades back. Harrison and Donnelly (2011), believe that "The phrase Smart Cities is not new. It may have its origins in the Smart Growth [Bollier, 1998] movement of the late 1990s, which advocated new policies for urban planning."By 2005 the term and idea got infused into the thinking of a number of technology companies viz. Siemens (in 2004) Cisco (in 2005) and IBM (in 2009). They used the idea as an opportunity to integrate technology in managing complex urban systems and provide seamless services of urban transportation, buildings, electricity, water supply, sanitation among others. They developed different models of technology-led innovations for the planning, development, and operation of cities. Real-time data collection and sharing through ICT-driven infrastructure is the emerging frontier of urban management. Cities like Songdo (South Korea), Masdar (UAE), PlanITValley (Portugal), Barcelona (Spain), Copenhagen (Denmark) among a host of others have already infused them into their system.

\section{Smart Cities: The Global Models}

Integration of technology, ICT, real-time data, connected devices, distributed sensors and internet technologies define the global models of a smart city. They are being used to collect valuable data, offer new services and improve the performance of the existing ones and thereby enhance the service delivery. A major role is played by mobile technologies and services in the process. The flow of real-time data is being used in managing traffic, urban transportation, natural disaster, water and electricity supply, solid waste management. It's also providing information about various services in the vicinity and so on. Innovations like geo-tagging help locate machinery and equipment and move them from one to another place quickly.

ICT and technology are being used for bringing innovation at different levels in the emerging models of smart cities around the world. In the city of Charlotte, North Carolina, US, a partnership programme named Envision Charlotte is being run between the city administration, office building owners and managers, electric and water utilities, mobile operators, technology vendors to improve energy efficiency in more than 10,000 sq. $\mathrm{ft}$. size buildings. The technology provides users with real-time data about their energy consumption. Busan's Green-u-City in South Korea is using an Integrated Operation Centre (IOC) with the help of an IP network and cloud infrastructure. It helps in the intelligent city management system and provides both free and commercial services to the city.

Extensive use of sensors is the backbone of smart city technology and communication system. Santander city in Spain, for example, has installed more than 12,000 sensors in the city in $35 \mathrm{~km}$ area to measure light, temperature, humidity, air quality, real-time position of vehicles among others. The data is also shared with the city dwellers. The sensors are both static and mobile which are fitted on public transport and other vehicles besides at fixed locations. Even citizens can download the sensor based app which collects real-time data as they move in the city. The kind of services these smart innovations are providing to Santander include: remote dimming of street lights on empty streets, collection of only filled garbage bins to reduce collection trips, traffic jam and accident information, realtime information of parking space, optimized use of watering in public parks to reduce wastage of water, measurement of air quality. (GSMA: Mobile Smart City Benchmarking Report, 2014)

\section{Smart Cities: India's Vision for the Cities of Future}

The intervention of emerging technology for urban transformation and to use them to create modern cities did not seem to be a priority under the centralized urban planning till the $11^{\text {th }}$ plan period. However, it was clearly articulated during the $12^{\text {th }}$ plan period when India acknowledged the need to revive its cities into smart cities and make them modern and contemporary. Smart cities are being envisioned as India's cities of the future. The nation which woke up to its urban challenges and the need to rejuvenate the ailing system recognized the need to adopt a completely transformative process. Thus the idea of a smart city was adopted as an opportunity to leverage IT integrated technology for urban upkeep, maintenance, governance and improving service delivery. Bholey (2016) writes, "in a simpler sense the prefix 'smart' is a euphemism for intelligent, apt and efficient application of technology and design for running the civic system." 
Nonetheless, like any other transformative process, the idea of a smart city also has a fair share of its criticism. Cavada et al. (2014) refer to one of the smart city's prominent critics Greenfield (2013) who believes cities have always been smart and their intelligence resides in the people. He (Greenfield) also calls the concept a 'rhetoric' which need to be properly defined. Krivy (2018) on the other hand indicate three main arguments that scholars make against smart city. They're: "it is incompatible with an informal character of the city, that it subjects the city to corporate power and that it reproduces social and urban inequalities." However, Barlow et. al. (2019) explain smart city as 'an eco-system of people, process and solution.' The short term vision for the smart city may be about the integration of technology in improving urban services and their management, but its long term vision encompasses quality of life improvements of citizens by the smart application of technologies (Galati, 2018). Thus, within the smart city framework possibilities of enhancing aspects like urban resilience, business, growth of citizens and services are also being explored.

Some of the most prominent apprehensions of India's foray into a smart city is on account of its being an idea better suited to developed nations. It is perceived, and rightly so, that the solution to manage complex urban problems is technology intensive which will require not only a huge financial investment but also new skills and training. Social inclusivity of this model and its perceived bias towards fulfilling the aspirations of the educated middle class have also been questioned. Because of the heavy dependence and application of IT in different sectors of urban management, security and safety of personal data are also being raised as a concern. Not only that, many urban experts feel that the whole process may finally help influential technology firms rather than individuals. Bhattacharya et al. (2015) point out that: "The Smart City Mission lacks clarity in its conceptualization. The focus seems to be on technology implementation, without an overall framework to understand the need and impact of the same. There is a lack of clarity in understanding the end (Smart City) and the means to reach the end (ICT)."Despite various apprehensions, the government of India launched the Smart city program in the year 2014 in a mission mode. The objective according to the Smart Cities Mission, Ministry of Housing and Urban Affairs (2017) is to:

"promote cities that provide core infrastructure and give a decent quality of life to its citizens, a clean and sustainable environment and application of 'Smart' Solutions. The focus is on sustainable and inclusive development and the idea is to look at compact areas, create a replicable model which will act like a light house to other aspiring cities.

Transformation of urban India is now being recognized as the need of the hour. Various steps are taken in the direction by putting in place several schemes and programmes such as JNNURM, AMRUT, Swachh Bharat Mission and Smart City Mission, etc. are meant to bring about the much needed transformation. Smart City Mission is the most ambitious policy of them all. While it carries on the welfare spirit of the plan period, it is also trying to find new ways to increase efficiency and improve service delivery through the integration of technology. The challenge of being compared with the global benchmarks like Songdo of South Korea, Masdar of UAE, PlanIT of Portugal and their like looms large. As per the Smart Cities Mission, the strategy for urban transformation includes:

- Pan-city initiative in which at least one Smart Solution is applied city-wide

- Develop areas step-by-step - three models of area-based developments

- Retrofitting

- Redevelopment and

- Greenfield

The above smart city strategy is expected to bring urban transformation by ensuring visible improvement in the delivery of water, sanitation and solid waste management, housing, transportation, IT infrastructure, etc. Figure 4 explains India's smart city priorities. 
Figure 5.

\section{Smart City}

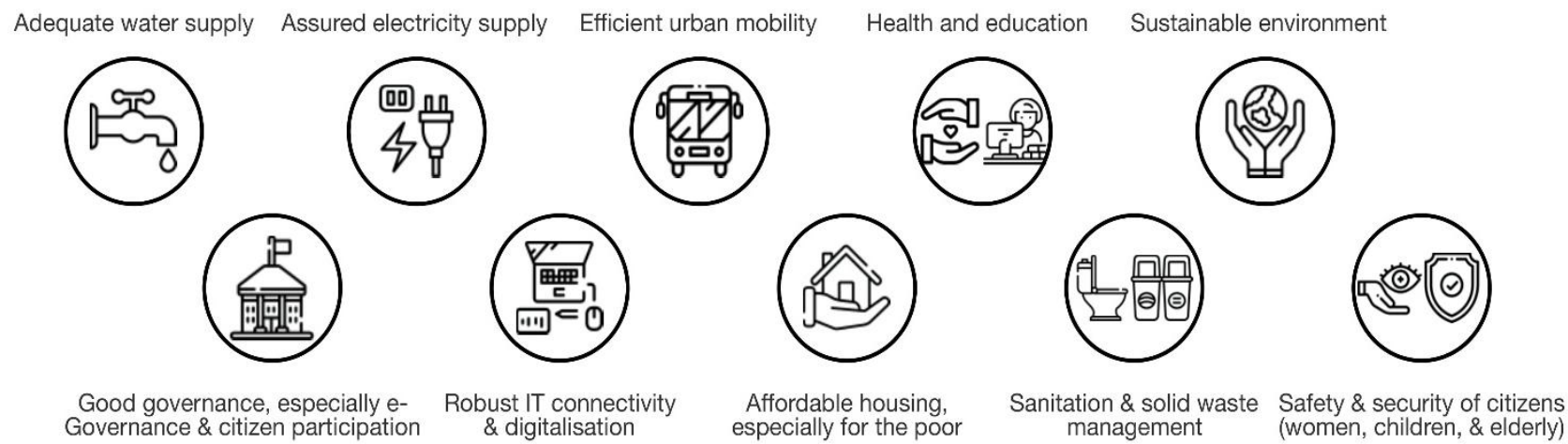

\section{Conclusion}

Successive urban plans in India largely look like an immediate response to the emerging urban needs of the day. They no doubt succeeded in solving the problems to an extent. However, they didn't envision the future of urbanization nor could they design long term strategic interventions to achieve urban transformation. India might have woken up to its urban challenges and imperatives a little late in the day, but it woke up at a time when its economic growth, technological competence, skills and experience in urban management are much improved as compared to the initial days of the plan period. So changes can be expected at a much faster pace. Transformation is a long arduous process, no matter whether it's socio-economic, political or urban. The complexity of society is what often hinders and delays the process. Bertolini (2017) observes "Achieving transformative change in the face of complexity is a difficult and seemingly paradoxical task. Development in each component of the system both enable and constraint development in other components." Urban transformation in India is also experiencing teething problems. However, shifting from the centralized era of planned development to the decentralized, even localized era of participatory development itself is a major transformative process in India's urbanization. Now, it's also being backed by various design and technological interventions.

It's interesting to see how Indian cities are identifying their own problems and developing solutions with the appropriate use of technology and ICT. The Greater Hyderabad Municipal Corporation (GHMC) for example has provided app based solution (My GHMC) to locate nearest public toilets. For monitoring cleanliness of the public toilets, it's timing, garbage collection at open spaces and sweeping, etc. GHMC has developed a Daily Monitoring Tool (DMT) app. Delhi Metro's DMRC app helps commuters find seamless connections between different routes of Metro. Online payment of electricity bills, house taxes, even generation of traffic offense fines through the monitoring cameras, in cities like Delhi, Ahmedabad, Hyderabad and many more is becoming part of urban governance. Connecting urban management with Digital India Programme meant to spearhead digital transformation is also playing a major role in improving urban public service delivery in recent years. The New Delhi Municipal Corporation app NDMC 311 besides connecting to other services also facilitates online registration for availing healthcare services at public hospitals. These innovations are also steps in the direction of urban transformation.

However, a city may be considered smart only when it carefully invests into its human and social capital to improve the quality of life. Such smart interventions are essential to bring about the much needed urban transformation in contemporary India. The transformation has to bring both qualitative and quantitative change to counterpoise the legacy of reluctant urbanization and make up the development deficit caused in the process. Well-planned urban transformation is the way forward to the smart city which has to be socially inclusive, economically viable and environmentally sustainable. Technology should not be the end rather the means for bringing urban transformation and building smart cities. India needs conscious and calibrated efforts to eventually achieve sustainable urban development. The programme of building smart city may just be the right incentive. 


\section{References:}

[1]. Ahluwalia, Isher Judge. Urban governance in India. Journal of Urban Affairs. Routledge. 2017. smartnet.niua.org/sites/default/files/resources/urban_governance_in_india.pdf Accessed 21 Jan. 2019.

[2]. Ahluwalia, Isher Judge., et al.Urbanization in India: Challenges, Opportunities and the Way Forward. Delhi. Sage Publications India Pvt. Ltd. 2014

[3]. Barlow, Mike and Cornelia Levy-Bencheton. Smart Cities Smart Future: Showcasing Tomorrow. New Jersey. Wiley, 2019.

[4]. Batra, Lalit. A review of Urbanization and urban policy in post-independent India, Working Paper Series, Centre for the Study of Law and Governance, Jawaharlal Nehru University, New Delhi, April 2009.

[5]. --------, A review of Urbanization and urban policy in post-independent India, Working Paper Series, Centre for the Study of Law and Governance, Jawaharlal Nehru University, New Delhi, April 2009.

[6]. Bertolini, Luca. Planning the Mobile Metropolis. London. Palgrave. 2017.

[7]. Bhattacharya, Shrimoyee, et al. Reconceptualising Smart Cities: A Reference Framework for India. Center for Study of Science, Technology and Policy, 2015. Accessed 21 Jan. 2019

niti.gov.in/writereaddata/files/document_publication/CSTEP\%20Report\%20Smart\%20Cities\%20Framew ork.pdf.

[8]. Bholey, Mihir. India's Urban Challenges and Smart Cities: A Contemporary Study. Scholedge International Journal of Business Policy \& Governance. Vol.03, Issue 03, 21. 2016, pp 17-35. [http://www.thescholedge.org/journals/] Accessed 12 Jan. 2019.

[9]. -------- India's Urban Challenges and Smart Cities: A Contemporary Study. Scholedge International Journal of Business Policy \& Governance. Vol.03, Issue 03, 21. 2016, pp 17-35. [http://www.thescholedge.org/journals/] Accessed 21 Jan. 2019.

[10]. Cavada, Marianna et al. Smart Cities: Contradicting Definitions and Unclear Measures. 2014. researchgate.net/publication/267763113_Smart_Cities_Contradicting_Definitions_and_Unclear_Measures Accessed 21 Jan. 2019.

[11]. Connected City: Mobile Smart City Benchmarking Report. Feb. 2014. gsma.com/iot/wpcontent/uploads/2014/02/2649_GSMA_benchmarking_Report_Web.pdf. Accessed 29 Jan. 2019.

[12]. Ernst \& Young. India's Growth Paradigm: How Markets beyond Metros Have Transformed. Ernst \& Young, 2017. ey.com/Publication/vwLUAssets/ey-indias-growth-paradigm/\$FILE/ey-indias-growth paradigm.pdfAccessed 10 Jan. 2019.

[13]. Galati, Stephen R. Funding a Smart City: From Concept to Actuality. In McClellan, Stan et. al. (Eds.) Smart Cities: Application, Technlogies, Standards and Driving Factors. Springer, 2018.

[14]. Gandhi, M. K. Village Swaraj. Ahmedabad. Navjivan Trust. 1962. p. 44.

[15]. Greenfield, A. This is Part I of The city is here for you to use: 'Against the smart city'. New York Do. 2013.

[16]. Harrison, Colin. and Ian A. Donnelly. A Theory of Smart Cities. journals.isss.org/index.php/proceedings55th/article/viewFile/1703/572Accessed 15 December, 2018.

[17]. Hauser, Philip M and Otis Dudley Duncan. The Study of Population: An Inventory and Appraisal. University of Chicago Press, 1959

[18]. India. Ministry of Housing and Urban Affairs. Jawaharlal Nehru National Urban Renewal Mission. 17 Jan. 2019. mohua.gov.in/cms/jawaharlal-nehru-national-urban-renewal-mission.php Accessed 17 Jan. 2019

[19]. India. Planning Commission. Urban Development. planningcommission.nic.in/hackathon/Urban_Development.pdf Accessed 18 Jan. 2019.

[20]. ---------. Urban Development. planningcommission.nic.in/hackathon/Urban_Development.pdf Accessed 18 Jan. 2019.

[21]. India. Ministry of Housing and Urban Affairs, What Is Smart City. Smart Cities Mission, 2017.smartcities.gov.in/content/innerpage/what-is-smart-city.php. Accessed 21 Jan. 2019.

[22]. India. Planning Commission. Eleventh Five Year Plan 2007-12: Volume III Agriculture, Rural Development, Industry, Services, and Physical Infrastructure. planningcommission.nic.in/plans/planrel/fiveyr/11th/11_v3/11th_vol3.pdf Accessed 23 Jan. 2019.

[23]. Indian Real Estate; unfolding the new era of growth. KPMG, 2017. assets.kpmg/content/dam/kpmg/in/pdf/2017/08/transformation-real-estate.pdfAccessed 6 Jan. 2019. 
[24]. Kamath, Lalitha and Yacoub Zachariah. IHSDP Programmes on Infrastructure and Governance Outcomes in Cities/ Towns in India: A Review of the State of Knowledge. Tata Institute of Social Science, 2015. www.tiss.edu/uploads/files/TISS_Working_Paper-7-Lalitha_Kamath.pdf Accessed 17 Jan. 2019.

[25]. Krivý, Maroš. Towards a critique of cybernetic urbanism: The smart city and the society of control. Planning Theory. SAGE Publications. 2018.

[26]. Lanjouw. P, and R. Murgai. 2010. —Size Matters: Urban Growth and Poverty in India 1983-2005, mimeo, Development Economics Research Group, the World Bank.

[27]. Lanjouw, Peter \&Murgai, Rinku. (2019). Urban Growth and Rural Poverty in India. researchgate.net/publication/264874552_Urban_Growth_and_Rural_Poverty_in_India Accessed 15 Nov. 2018.

[28]. Marshall, Stephen. (2012). Sustainable Urbanism in Evolution. In Tigran Haas (Ed.) Sustainable

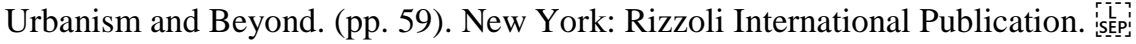

[29]. Mathur, M.P. Finances and Functioning of Urban Local Bodies: A Situation Report. In Morris, Sebestianet. al. (Eds.) India Infrastructure Report 2001: Issues in Regulation and Market Structure. Delhi. Oxford University Press. 2001.

[30]. McGranahan, Gordon and Satterthwaite, DavidUrbanisation Concepts and Trends. 2014,pubs.iied.org/pdfs/10709IIED.pdf.Accessed 20 Nov. 2018.

[31]. Montgomery, R. et al.(eds.)Cities Transformed: Demographic Change and its Implications in the Developing World.London: Earthscan, 2004.

[32]. Mukherjee, Jenia. Indian Urban Trajectories: Addressing 'Sustainability' across Micro-political Settings. In Mukherjee, Jenia. (Ed.) Sustainable Urbanization in India: Challenges and Opportunities. Singapore. Springer, 2018.

[33]. Paul, Samuel. Urban Infrastructure and Governance. In Ramesh, et.al. (Eds.) Urban Growth and Governance in India an Overview.(pp. 3) London: Routledge, 2010

[34]. Raheja, B.D. Urban India and Public Policy, Somaiya publishers, New Delhi, 1973, p. 7.

[35]. Report of the Study Group on NCR Policy Zones, Demographic Profile and Settlement Pattern. National Capital Region Planning Board, New Delhi. 2001. ncrpb.nic.in/pdf_files/SG1.pdf Accessed 16 Jan. 2019.

[36]. Routray J. K. 'Urban and Regional Planning in Practice in India' Habitat International; vol. 17, No.3, 1993.

[37]. Sassen, S. The Global City: New York, London, Tokyo. ( $2^{\text {nd }}$ Edn.) Princeton, Princeton University Press. 2001.

[38]. Sharma, Purobi. IOSR Journal of Humanities and Social Science (IOSR-JHSS) Volume 19, Issue 3, Ver. VII (Mar. 2014), PP 45-52. iosrjournals.org/iosr-jhss/papers/Vol19-issue3/Version7/G019374552.pdfAccessed 31 Dec. 2018.

[39]. Thompson, W.S. Encyclopedia of Social Sciences, Vol. XV, Macmillan (1935), p. 189.

[40]. Tiwari, Piyush., Nair, Ranesh., Ankinapalli, Pavan., Rao, Jyoti., Hingorani, Pritika., Gulati, Manisha. India's Reluctant Urbanization: Thinking Beyond. 2015th ed., Palgrave Macmillan,

[41]. United Nations. Department of Economic and Social Affairs. $16 \quad$ May, 2018. un.org/development/desa/en/news/population/2018-revision-of-world-urbanizationprospects.htmlAccessed Jan. 10, 2019.

[42]. Understanding India's economic geography. McKinsey. 2014. mckinsey.com/featured-insights/asiapacific/understanding-indias-economic-geographyAccessed 20 Dec. 2018

[43]. Urban Transformation in India: Inherently Dis-Equalising? Centre for Policy Research, 25 Aug. 2015 , cprindia.org/sites/default/files/Panel\%20Discussion\%2025\%20August\%20FINAL.pdf. Accessed 8 Jan. 2019.

[44]. Vale and Vale. Green Architecture: Towards a more sustainable future. London. Thames \& Hudson, 1996.

[45]. World Urbanization Prospects: The 2018 Revision. United Nations, 2018, population.un.org/wup/Publications/Files/WUP2018-KeyFacts.pdf. Accessed 8 Jan. 2019.

[46]. Worldometers. worldometers.info/world-population/india-population/Accessed 25 Dec. 2018. 